\title{
Heritable artificial sex chromosomes in the medaka, Oryzias latipes
}

\author{
H Otake ${ }^{1}$, H Masuyama ${ }^{2}$, Y Mashima ${ }^{3}$, A Shinomiya ${ }^{4}$, T Myosho ${ }^{1}$, Y Nagahama ${ }^{5}$, M Matsuda ${ }^{6}$, \\ $S$ Hamaguchi ${ }^{1}$ and M Sakaizumi ${ }^{1}$ \\ ${ }^{1}$ Institute of Science and Technology, Niigata University, Niigata, Japan; ${ }^{2}$ United Graduate School of Agricultural Science, Tokyo \\ University of Agriculture and Technology, Tokyo, Japan; ${ }^{3}$ Department of Environmental Science, Faculty of Science, Niigata University, \\ Niigata, Japan; ${ }^{4}$ Department of Biology, Keio University, Yokohama, Japan; ${ }^{5}$ Laboratory of Reproductive Biology, National Institute \\ for Basic Biology, Okazaki, Japan and ${ }^{6}$ Center for Bioscience Research and Education, Utsunomiya University, Utsunomiya, Japan
}

\begin{abstract}
Chromosomal sex determination is widely used by vertebrates, however, only two genes have been identified as master sex-determining genes: SRY/Sry in mammals and $D M Y$ in the teleost medaka. Transfer of both genes into genetically female $(\mathrm{XX})$ individuals can induce male development. However, transgenic strains have not been established in both cases because of infertility of the transgenic founders in mammals and low germline transmission rates in medaka. In this study, we used a BAC clone containing DMY in a $117 \mathrm{~kb}$ genomic region and two types of fluorescent marker to establish two $D M Y$-transgenic medaka strains. In these strains, exogenous $D M Y$ is completely linked to a male phenotype and early gonadal development is not different from that of the wild-type strain. Sex-linkage analysis showed that the exogenous $D M Y$ was located on linkage group (LG)
\end{abstract}

23 in one strain and on LG 5 in the other strain, whereas the sex chromosome in medaka is on LG 1. Real-time PCR analysis indicated that these strains have multiple copies of $D M Y$ and higher $D M Y$ expression levels than the wild-type strain. These results showed that LGs 23 and 5 function as sex chromosomes in the two strains, respectively. This is not only the first example of the artificial generation of heritable sex chromosomes in vertebrates but also the first evidence showing plasticity of homomorphic sex chromosomes. This plasticity appears to be a characteristic of lower vertebrates and the underlying cause of frequent sex chromosome switching, recently reported in several fish and frog species.

Heredity (2010) 105, 247-256; doi:10.1038/hdy.2009.174; published online 9 December 2009

Keywords: sex chromosome; sex-determining gene; medaka; DMY

\section{Introduction}

Genetic sex determination, based on sex chromosomes, is widely used by many vertebrates. The sex chromosome can be defined as the chromosome containing a single master sex-determining gene that initiates sexual development; $X$ and $Y$ in a male heterogametic $(X X / X Y)$ system or $\mathrm{Z}$ and $\mathrm{W}$ in a female heterogametic (ZZ/ZW) system. To date, only two genes have been identified as master sex-determining gene in vertebrates: SRY/Sry in mammals (Gubbay et al., 1990; Sinclair et al., 1990) and $D M Y$ (the DM-domain gene on the $\mathrm{Y}$ chromosome) in the teleost medaka, Oryzias latipes (Matsuda et al., 2002; Nanda et al., 2002).

The $\mathrm{X}$ and $\mathrm{Y}$ chromosomes in mammals are highly differentiated. Crossovers occur only in a small homologous region, designated the pseudoautosomal region. $S R Y$ is located on the degenerated Y chromosome, which is small, gene poor, repetitive and half heterochromatic. The gene content of the $\mathrm{Y}$ varies between species, but all groups of therian mammals possess an SRY gene on the $Y$ chromosome (Waters et al., 2007). On the other hand, $\mathrm{X}$ and $\mathrm{Y}$ chromosomes are homomorphic in medaka.

Correspondence: Professor M Sakaizumi, Institute of Science and Technology, Niigata University, Niigata 950-2181, Japan.

E-mail: sakaizum@env.sc.niigata-u.ac.jp

Received 11 September 2009; revised 27 October 2009; accepted 5 November 2009; published online 9 December 2009
Sex chromosomal crossovers occur over almost the entire chromosome, whereas $D M Y$ is located in a very small Y-specific region. In contrast to the widespread distribution of $S R Y$ / Sry in mammals, DMY is found only in medaka and in $O$. curvinotus, the closest relative to medaka (Matsuda et al., 2003; Tanaka et al., 2007). DMY encodes a putative transcription factor belonging to the family of DM-domain proteins. All members of this protein family have a conserved DNA-binding motif originally found in two proteins, DSX in Drosophila melanogaster and MAB-3 in Caenorhabditis elegans (Raymond et al., 1998). One of these DM-domain genes, DMRT1 (DM-related transcription factor 1), has been implicated in male sexual development in vertebrates (Zarkower, 2001). The cDNA sequences of medaka DMY and DMRT1 show a high similarity (about $80 \%$ ), and comparative analysis of $X$ and $Y$ chromosomes indicated that DMY arose through a duplication event of the autosomal DMRT1 gene (Kondo et al., 2006). This DMRT1 duplication event is estimated to have occurred about 10 million years ago, suggesting that the medaka $\mathrm{Y}$ chromosome is one of the youngest male sex-determining systems in vertebrates.

The male-determining functions of both SRY/Sry and $D M Y$ were shown by transgenic experiments that showed testis differentiation and male development of chromosomally female (XX) individuals (Koopman et al., 1991; Matsuda et al., 2007). However, no transgenic strains, in any species, have been established. Srytransgenic mice showed normal copulatory behavior 
but were sterile because germ cells are prevented from progressing beyond prospermatogonia. In medaka, although transgenic fish injected with a BAC clone containing $D M Y$ in a $117 \mathrm{~kb}$ genomic region show testis differentiation with spermatogenesis, low germline transmission rates have prevented the establishment of transgenic strains. Here, with the use of two types of fluorescent marker integrated into the BAC clone, we established two DMY-transgenic medaka strains, in which the exogenous $D M Y$ gene determined the sex of each individual. We show that linkage groups (LGs) 23 and 5 function as sex chromosomes in the two strains, respectively. This is the first example of the generation of artificial sex chromosomes in vertebrates.

Our results also highlight the property of homomorphic sex chromosomes. Many species of fish and amphibians, including medaka, have homomorphic sex chromosomes. Recently, several comparative studies have provided evidence that different sex chromosomes and sex-determining systems have evolved in closely related fish species (Woram et al., 2003; Peichel et al., 2004; Takehana et al., 2007) and in the same species of frog (Ogata et al., 2003). The present results show that in vertebrates possessing homomorphic sex chromosomes, autosomes can easily become sex chromosomes. The frequent switching of sex chromosomes appears to be based on the plasticity of homomorphic sex chromosomes. This plasticity is characteristic of lower vertebrates and is not found in higher vertebrates, such as mammals and birds.

\section{Methods}

\section{Strains and sexing}

We used the Hd-rR inbred strain of medaka, which was derived from the Southern population. In this strain, because a sex-linked pigment gene, $R$, is located on the $Y$ chromosome, the female $X^{r} X^{r}$ has a white body color and the male $X^{r} Y^{R}$ has an orange-red body (Aida, 1921). The genetic sex of each individual was confirmed by genomic PCR of fin clip DNA in accordance with an earlier method (Shinomiya et al., 2004). As DMY in the transgene construct was derived from the HNI inbred strain, which is derived from the Northern population, the exogenous $D M Y$ and the host $D M Y$ could be distinguished by a polymorphic genomic PCR product.

F0 XX males with germline transmission of the exogenous DMY were mated with Hd-rR strain female. To maintain the transgenic strains, exogenous DMYpositive males were outcrossed to a female of Hd-rR strain in the subsequent generations.

\section{BAC modification}

We inserted two fluorescent reporter genes into the DMY BAC: a germ-cell-specific olvas promoter driving green fluorescent protein (GFP) and a crystal-lens-specific crystallin- $\gamma M 2$ promoter driving red fluorescent protein (RFP). The two fluorescent reporters were inserted into the BAC vector using a Quick and Easy BAC Modification kit (Gene Bridges GmbH, Dresden, Germany), which relies on homologous recombination in Escherichia coli.

\section{Microinjection}

Fertilized eggs were collected within 15 min of spawning. The attached filaments were scraped off the chorion onto a piece of paper. Eggs were microinjected as described earlier (Kinoshita et al., 1996). We used DNA at $10 \mathrm{ng}^{-1} \mathrm{l}^{-1}$ in Yamamoto's solution $(133 \mathrm{mM} \mathrm{NaCl}$, $2.7 \mathrm{mM} \mathrm{KCl}, 2.1 \mathrm{mM} \mathrm{CaCl}, 0.2 \mathrm{mM} \mathrm{NaHCO} 3, \mathrm{pH} 7.3)$. The injected eggs were incubated at $27^{\circ} \mathrm{C}$.

\section{In situ hybridization}

Testes were dissected from adult males, fixed with $4 \%$ paraformaldehyde in $0.1 \mathrm{M}$ phosphate buffer $(\mathrm{pH} 7.4)$ at $4{ }^{\circ} \mathrm{C}$ overnight, embedded in paraffin and cut into $5 \mu \mathrm{m}$ cross-sections. Digoxigenin-labeled antisense RNA probes were generated by in vitro transcription with DIG RNA labeling kit (Roche, Basal, Switzerland) from a DMY cDNA plasmid as described earlier (Kobayashi et al., 2004). Sections were deparaffinized, hydrated, treated with proteinase $\mathrm{K}\left(10 \mu \mathrm{g} \mathrm{ml}^{-1}\right)$ at $37^{\circ} \mathrm{C}$ for $7 \mathrm{~min}$ and hybridized with the DIG-labeled antisense RNA probes at $57^{\circ} \mathrm{C}$ for 18-24h. Hybridization signals were detected using an alkaline phosphatase-conjugated anti-DIG antibody (Roche) with NBT/BCIP (Roche) as the chromogen.

\section{Histological analysis}

For histological analysis and the counting of germ-cell numbers, $F_{3}$ transgenic-strain embryos were dissected into head and body segments. The body portions were fixed overnight in Bouin's fixative solution and then embedded in paraffin. Each dissected head was used to confirm the presence or absence of exogenous DMY by PCR; $5 \mu \mathrm{m}$ cross-sections of gonad were cut serially and, after H\&E staining, all of the germ cells in each of the fry were counted. After cell counting, the mean and standard error were calculated for each of group DMY-positive and -negative groups. Differences between groups were evaluated statistically using the paired $t$-test.

\section{Transgene mapping}

We used M-marker (Kimura et al., 2004) to search for the nearest DNA marker to the exogenous DMY. M-marker is a set of 48 expressed sequence tag markers (two expressed sequence tags on each of 24 chromosome pairs); each DNA marker shows a length polymorphism between the Southern and Northern strains. As DMYtransgenic strains were derived from a Southern inbred strain (Hd-rR), DMY-transgenic $\mathrm{F}_{2}$ males were mated with a Northern inbred strain, Kaga. $F_{3}$ transgenepositive male progeny were mated with $\mathrm{Hd}-\mathrm{rR}$ strain females to obtain the backcross generation. The exogenous DMY was expected to be located in the Hd-rR homozygous region of transgene-positive fish or in the Hd-rR/Kaga heterozygous region of transgene-negative fish in the backcross generation. We calculated the concordance rate by adding together the ratio of $\mathrm{Hd}-\mathrm{rR}$ homozygous fish to transgene-positive fish and that of Hd-rR/Kaga heterozygous fish to transgene-negative fish for each M-marker (Supplementary Figure 1). We used 28 and 27 backcross individuals for mapping in transgenic strains 1 and 2, respectively.

\section{Quantification of transgene copy number and of DMY expression levels}

Copy numbers were quantified using genomic DNA from the tail muscle. Dissected tail muscle was placed in 
$700 \mu \mathrm{l}$ of $100 \mathrm{mM}$ EDTA, $50 \mathrm{~mm}$ Tris ( $\mathrm{pH} 8.0), 100 \mathrm{mM}$ $\mathrm{NaCl}, 1 \%$ sodium dodecyl sulfate and $100 \mu \mathrm{g} \mathrm{ml}^{-1}$ of proteinase $\mathrm{K}$, and homogenized. The homogenate was incubated at $55^{\circ} \mathrm{C}$ for $3 \mathrm{~h}$. The lysate was purified using phenol-chloroform and DNA was precipitated with isopropyl alcohol, as described earlier (Shinomiya et al., 1999). The purity and concentration of the DNA were determined with a NanoDrop ND-1000 spectrophotometer (Thermo Scientific, Wilmington, MA, USA). The DNA concentrations of all samples were adjusted to give a total of $20 \mathrm{ng}$ for each real-time PCR assay. Primers were designed to amplify a $99 \mathrm{bp}$ fragment of DMY intron 4 (forward 5'-GGGTTTGCTTTTCTGCTTTCTGATTTC-3' and reverse 5'-AACTATTTTTACAGGCCCAGAATTAA-3') and a $128 \mathrm{bp}$ fragment of $\beta$-actin (forward $5^{\prime}$-CTAC GTAGGTGATGAAGCCCAGAG-3' and reverse $5^{\prime}$ TCAGCTCATTGTAGAAGGTGTGGT-3'). SYBR Green PCR master mix (Takara Bio, Otsu, Japan) was used in accordance with the manufacturer's protocol in an ABI 7000 real-time PCR instrument (Applied Biosystems, Foster City, CA, USA). The PCR conditions were $1 \mathrm{~min}$ at $94^{\circ} \mathrm{C}$, followed by 40 cycles of $5 \mathrm{~s}$ at $95^{\circ} \mathrm{C}$ and $30 \mathrm{~s}$ at $65^{\circ} \mathrm{C}$. To confirm that the amplified PCR products were specific to $D M Y$, we determined their melting temperatures from the dissociation curves. The fact that the melting temperature was the same for each product indicated that the same product was amplified from all the DNA samples. Direct sequencing confirmed that each product was amplified from the DMY gene. DMY copy number was determined by the comparative $\mathrm{Ct}$ method (Livak and Schmittgen, 2001; Pfaffl, 2001) as a relative value to the Hd-rR. ${ }^{H N I}$ congenic strain (Matsuda et al., 1998). Real-time PCR efficiencies of target gene (DMY) and reference gene ( $\beta$-actin) are same (Supplementary Figure 2a). The male of the Hd-rR. ${ }^{\text {HNI }}$ strain has a genetic background derived from the Hd-rR strain, and has only the chromosomal region including $D M Y$ from the HNI strain in its $\mathrm{Y}$ chromosome. Thus, $\mathrm{Ct}$ values from the Hd-rR. $Y^{\mathrm{HNI}}$ strain were set to 1 , and sample copy numbers were calculated as $2^{-\Delta \mathrm{Ct}}$

Expression levels were quantified using RNA from the body trunks of fry on hatching day. The purity and concentration of RNAs were determined using a NanoDrop ND-1000 spectrophotometer (Thermo Scientific), and concentrations were adjusted to give a total of $20 \mathrm{ng}$ for each real-time assay. Primers were designed to amplify a $217 \mathrm{bp}$ fragment of $D M Y$ exons 2 and 3 (forward 5'-CGGAACCACAGCTTGAAGACC-3' and reverse $5^{\prime}$-CTCCGGCTTCATTCTTCACCAC-3') and a $130 \mathrm{bp}$ fragment of elongation factor 1 (Elf1a) (forward 5'-CACCGGTCACCTGATCTACA-3' and reverse 5'-GCT CAGCCTTGAGTTTGTCC-3'). A One Step SYBR PrimeScript RT-PCR kit (Takara Bio) was used in accordance with the protocol of the manufacturer of the ABI 7000. The PCR conditions were $5 \mathrm{~min}$ at $42^{\circ} \mathrm{C}, 10 \mathrm{~s}$ at $95^{\circ} \mathrm{C}$, then 40 cycles of $5 \mathrm{~s}$ at $95^{\circ} \mathrm{C}$ and $31 \mathrm{~s}$ at $65^{\circ} \mathrm{C}$. The melting temperature and direct sequence analysis confirmed that each product had been amplified from $D M Y^{H N I}$. $\mathrm{Ct}$ values from the Hd-rR. $\mathrm{Y}^{\mathrm{HNI}}$ strain were set to 1 and the relative expression levels (as $2^{-\Delta \Delta C T}$ ) were calculated after correction (as $2^{-\Delta \mathrm{CT}}$ ) against the $\mathrm{Ct}$ value for Elf1a. Real-time PCR efficiencies of target gene (DMY) and reference gene (Elf1a) are same (Supplementary Figure 2b). All real-time quantitative PCR experiments were performed three times.

\section{Results}

\section{Establishment of DMY-transgenic strains}

An earlier study showed that a DMY BAC clone containing a $60 \mathrm{~kb}$ upstream region, a $56 \mathrm{~kb}$ coding region and a $1.4 \mathrm{~kb}$ downstream region could mimic the expression pattern of $D M Y$ during the period of sex determination in medaka (Matsuda et al., 2007). To facilitate the screening of transgene-positive fish, we integrated genes encoding GFP and RFP into this BAC clone (Figure 1a). GFP was regulated by the olvas promoter, a medaka vasa homolog (Shinomiya et al., 2000). Olvas-GFP signals were observed in the gonad on hatching day (Figure 1b). The usefulness of olvas-GFP for isolating candidate founders with germline integration capability in the $\mathrm{F}_{0}$ generation has been described earlier (Tanaka et al., 2001). RFP was regulated by a $\gamma M 2$ crystallin homolog promoter (M Matsuda, unpublished
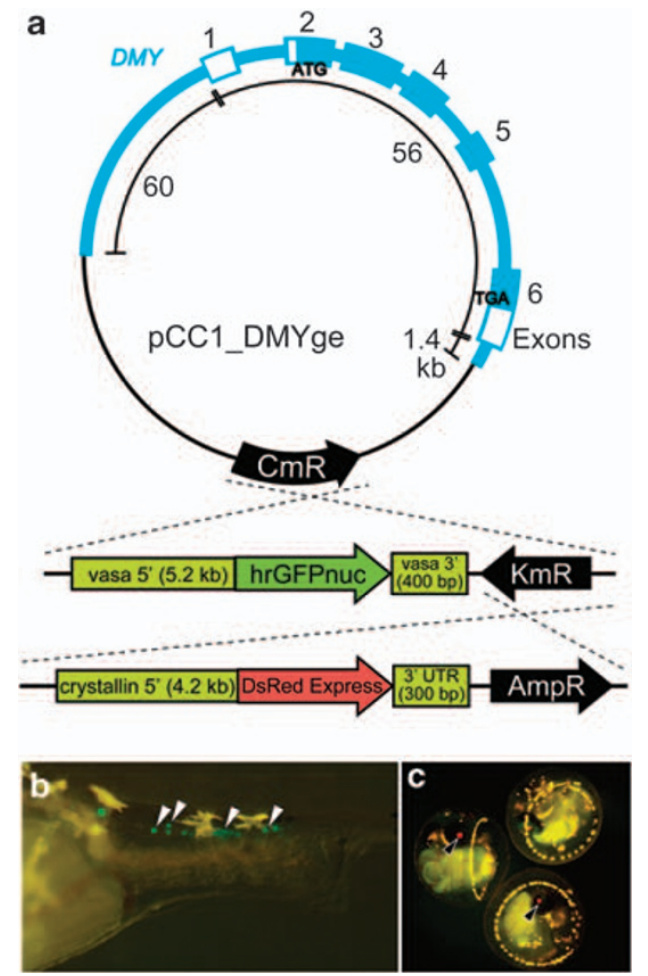

Figure 1 Transgene construct and expression of fluorescent markers in the stable transgenic lines. (a) Structure of the BAC clone containing the DMY genomic region. DMY gene comprises six exons and the translation start (ATG) and termination (TGA) site are located in exons 2 and 6, respectively. The numbers inside the circle indicate the length of upstream, gene coding and downstream region of the DMY gene contained in the BAC construct. A fragment encoding olvas-GFP and a kanamycin resistance gene was integrated into the ORF of the chloramphenicol resistance gene of the BAC construct. A fragment encoding crystallin-RFP and an ampicillin resistance gene was then integrated into the ORF of the kanamycin resistance gene. (b, c) Representative fluorescence microscopy images at 7 days after hatching (b) and 6 days after fertilization (c). (b) Lateral view, anterior is on the left and the dorsal side is up. The gonad lies dorsal to the gut. In the DMY-transgenic lines, green and red signals were observed in the gonad $(\mathbf{b})$ and the eye (c). GFP and RFP proteins were localized specifically in the germ cells (indicated by white arrowheads in b) and the lens (indicated by black arrowheads in c), respectively. 

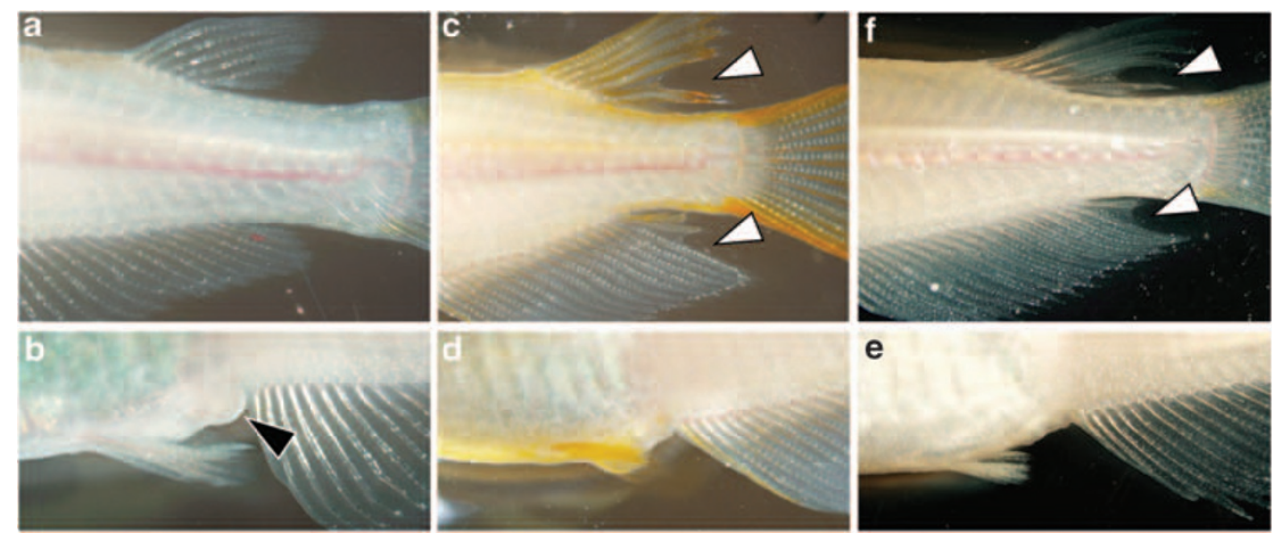

Figure $2 X X$ sex-reversed males observed in F0-transgenic fish. Representative images of the secondary sex characteristics of normal XX female $(\mathbf{a}, \mathbf{b})$, normal XY male (c, d), and DMY-injected XX male (e, f). Both dorsal and anal fins of males are sharp and have a slit (indicated by white arrowheads), whereas rounded anal fins and developed urogenital papillae (indicated by black arrowhead) are characteristic of females.

data). Crystallin-RFP signals were clearly observed in the eye from 3 days after fertilization (Figure 1c). The high intensity of these signals indicated that crystallin-RFP was highly effective for screening $\mathrm{F}_{1}$ generation progeny that had the heritable transgene. The modified BAC construct was injected into 897 one-cell-stage embryos of the inbred strain Hd-rR. On hatching day, we screened for fry that had green signals in the gonad and were therefore considered strong candidates for germlinetransmitting founders. We obtained 57 olvas-GFP-positive fry. After they had grown to adulthood, 5 of the 15 XX fish had male secondary sex characteristics (Figure 2). The XX males were mated with Hd-rR females, and all matings produced fertilized eggs, showing that the $X X$ fish were functional males. Two (ID Nos. 1 and 4) out of five F0 XX males produced embryos that had red signals in the eye, indicating that these progeny had inherited the transgene (Table 1). Genomic PCR analysis revealed that all $F_{1}$ crystallin-RFP-positive fish had the exogenous $D M Y$ gene, and they all developed into male adults. In subsequent generations, the male phenotype was completely linked to the presence of the exogenous DMY gene in both lines (Table 2). These results show the establishment of two DMY-transgenic strains in which exogenous DMY determined the sex of individuals. The strains derived from ID Nos. 1 and 4 XX males are hereafter referred to as strains 1 and 2, respectively.

\section{Characterization of DMY-transgenic strains}

We then examined the genetic and developmental characteristics of the $D M Y$-transgenic strains. To validate the expression patterns of the exogenous DMY, we performed RT-PCR on several tissues and in situ hybridization on adult testes. The exogenous $D M Y$ were expressed only in the testes (Figure 3a) and $D M Y$ transcripts were localized in the somatic cells surrounding germ cells in both DMY-transgenic strains (Figure 3b). These results show that the exogenous $D M Y$ recapitulate the expression patterns of the endogenous $D M Y$. Next, to examine early gonadal development, we performed histological observations on hatching day. In medaka, it is well known that the first
Table 1 Screening of germline transmission

\begin{tabular}{lcc}
\hline ID no. of F0 XX male & \multicolumn{2}{c}{ Number of $F_{1}$ embryos } \\
\cline { 2 - 3 } & Crystallin-RFP (-) & Crystallin-RFP (+) \\
\hline 1 & 158 & 60 \\
2 & 149 & 0 \\
3 & 39 & 0 \\
4 & $>50$ & 10 \\
5 & $>50$ & 0 \\
\hline
\end{tabular}

Abbreviation: RFP, red fluorescent protein.

Table 2 Phenotypic sex of transgenic strains

\begin{tabular}{|c|c|c|c|c|c|}
\hline \multirow{2}{*}{$\begin{array}{l}\text { ID no. of } \\
X X \text { male }\end{array}$} & \multirow[t]{2}{*}{ Generation } & \multicolumn{2}{|c|}{ Exogenous DMY (-) } & \multicolumn{2}{|c|}{ Exogenous DMY (+) } \\
\hline & & Female & Male & Female & Male \\
\hline 1 & $\mathrm{~F}_{1}$ & 14 & 0 & 0 & 11 \\
\hline \multirow{4}{*}{ (Strain 1) } & $F_{2}$ & 19 & 0 & 0 & 6 \\
\hline & $\mathrm{F}_{3}$ & 14 & 0 & 0 & 11 \\
\hline & $\mathrm{F}_{4}$ & 6 & 0 & 0 & 6 \\
\hline & $\mathrm{F}_{5}$ & \multicolumn{2}{|c|}{ ND } & 0 & 20 \\
\hline \multirow{3}{*}{$\begin{array}{l}4 \\
\text { (Strain 2) }\end{array}$} & $\mathrm{F}_{1}$ & \multicolumn{2}{|c|}{ ND } & 0 & 10 \\
\hline & $\mathrm{F}_{2}$ & 12 & 0 & 0 & 22 \\
\hline & $\mathrm{F}_{3}$ & 9 & 0 & 0 & 25 \\
\hline
\end{tabular}

Abbreviation: ND, not determined.

indication of morphological sex differentiation is the difference in the number of germ cells between the sexes at hatching. The germ cells in females continue to proliferate and then enter meiosis, whereas the male germ cells arrest in mitosis just before hatching (Satoh and Egami, 1972). Therefore, germ cells in XX individuals outnumber those in $X Y$ individuals at hatching (Kobayashi et al., 2004). We counted the number of germ cells at hatching in the two DMY-transgenic strains. In both strains, transgene-negative fish had significantly more germ cells than transgene-positive fish-the same 
a

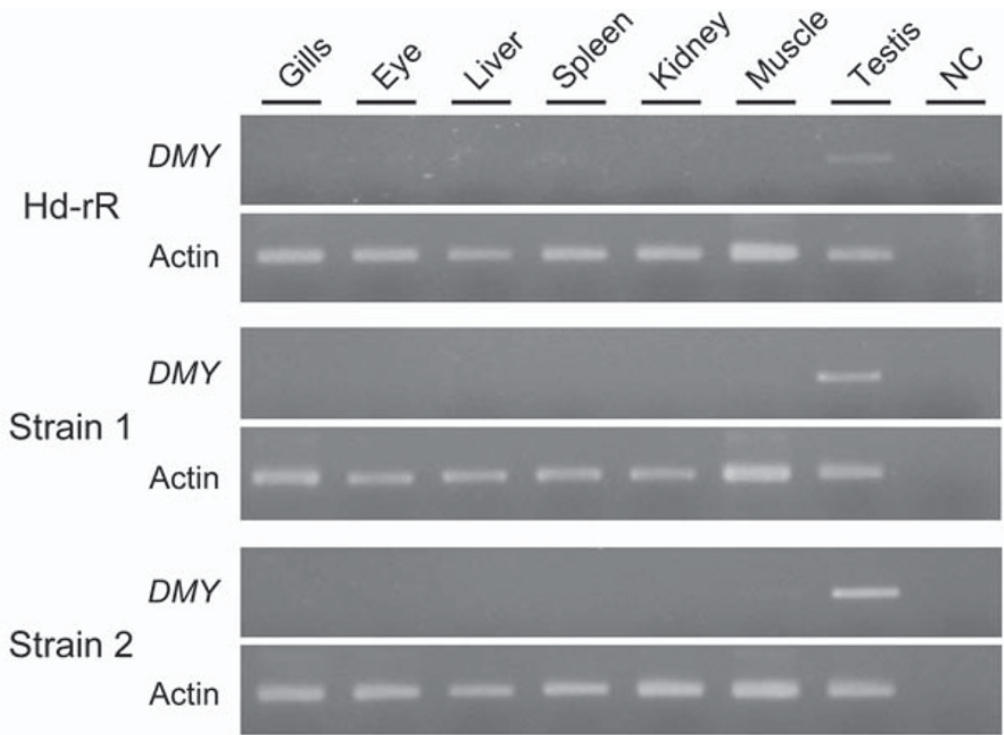

b

Hd-rR

Strain 1

Strain 2

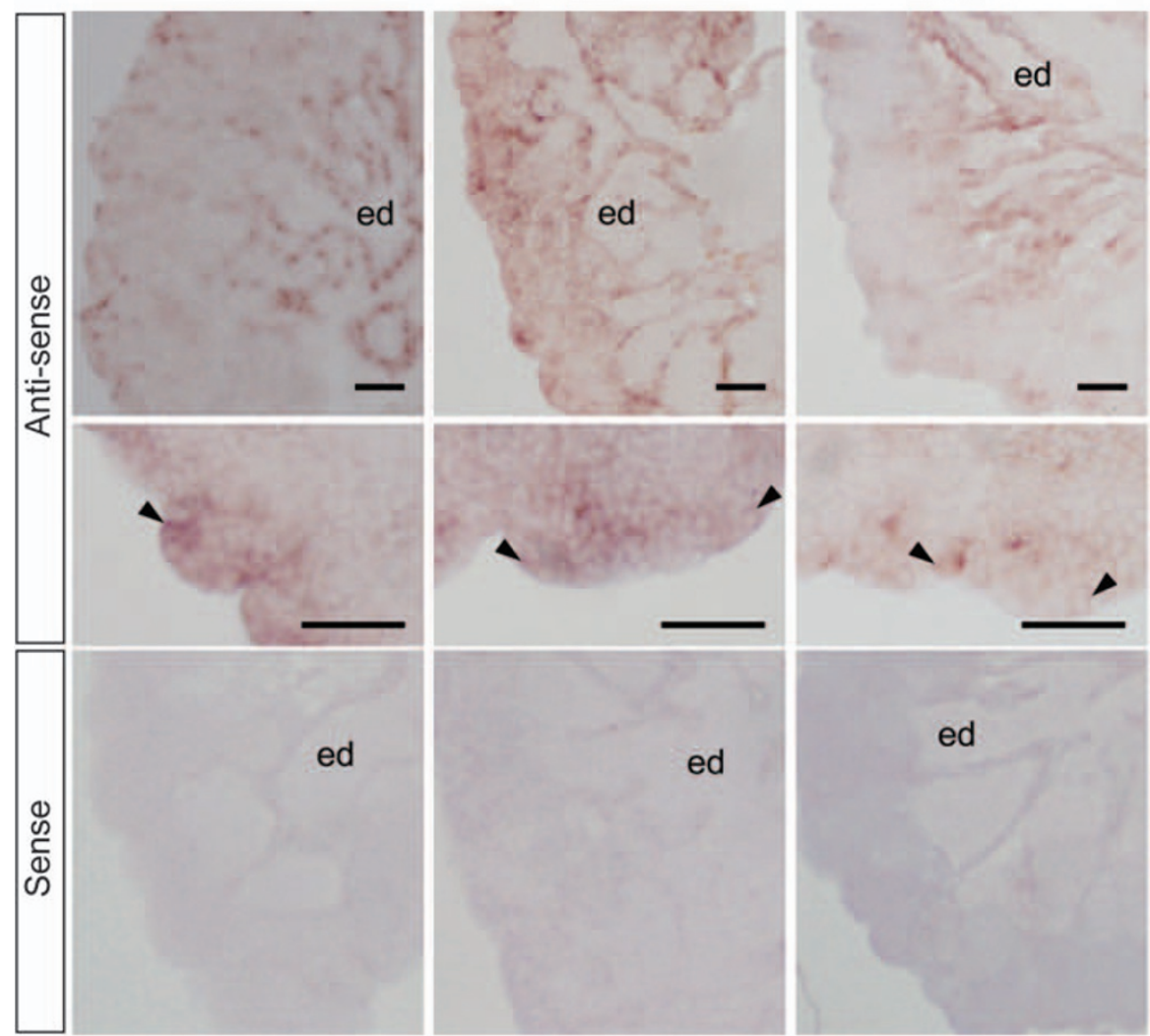

Figure 3 Spatial expression patterns of the exogenous DMY. (a) RT-PCR analysis using total RNA extracted from various tissues. A 404-bp DMY product was amplified. As a control, the same RNA extracts were used to amplify a 322-bp product of the ubiquitously expressed $\beta$ actin gene. (b) In situ hybridization for DMY in the adult testes of Hd-rR inbred strain, DMY-transgenic strains 1 and 2. Arrowheads, germ cell-supporting cells; ed, efferent duct; Scale bar, $20 \mu \mathrm{m}$.

pattern as in Hd-rR XX and XY individuals (Figure 4). We also examined early gonadal development according to the presence or absence of diplotene oocytes at 10 days after hatching. In this period, the female germ cells are recognizable as oocytes. The gonads of female fry contain germ cells in mitosis and in meiotic prophase (Figure 5a), whereas those of male fry contain only gonia (Figure $5 b$ ). In both strains, transgene-negative fish (5 in each strain) had diplotene oocytes (Figures $5 \mathrm{c}$ and e), whereas transgene-positive fish (13 in each strain) had no oocytes (Figures $5 \mathrm{~d}$ and $\mathrm{f}$ ). No morphological differences were observed between normal males and transgenic-strain 
252

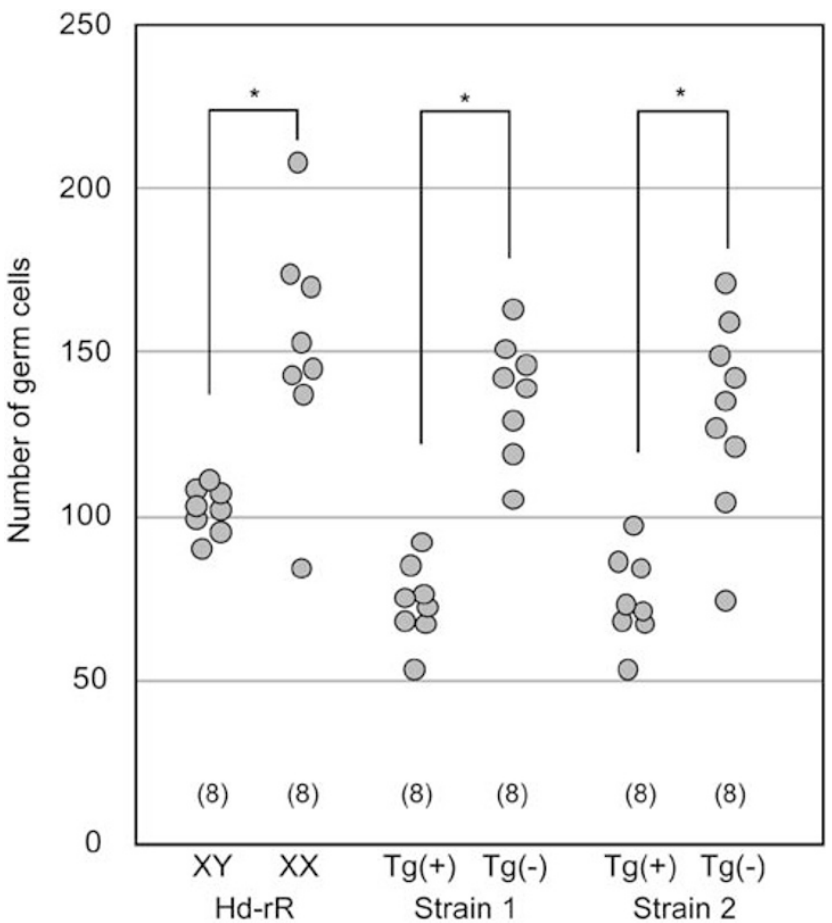

Figure 4 Germ cell numbers in the Hd-rR inbred strain and in the DMY-transgenic strains on hatching day. Numbers of samples are shown in parentheses. There were significant differences between the germ cell numbers in $X X$ and $X Y$ fish of the Hd-rR strain and the transgene-positive and -negative fish in both DMY-transgenic strains $\left({ }^{*} P<0.01\right)$.

males at 10days after hatching (Figures 5b, d, e). These results show that early gonadal development in these strains did not differ from that of the wild-type strain, suggesting that the exogenous DMY gene functioned identically to the wild-type DMY. In addition, two observations, there is no morphological differences between normal males and transgenic-strain males in the histological examination of adult testes (Supplementary Figure 3) and transgenic-strain males are fully fertile at least in the laboratory condition, indicate that transgene-positive male fish is functionally equivalent to wild-type males.

The karyotype of medaka consists of 24 chromosome pairs, and DMY is located on LG 1 . We performed a linkage analysis to reveal the locus of the exogenous DMY. In strain 1, a marker on LG 23, MF01SSA036A04, had a $100 \%$ concordance rate with the exogenous $D M Y$ (Figure 6a). To narrow down the candidate locus, we examined three additional markers (MF01FSA018C03, OLb1905f and OLe1111 g). OLb1905f had a concordance rate of $96.2 \%$, and that of OLe $1111 \mathrm{~g}$ was $100 \%$, indicating that exogenous $D M Y$ was located on the telomeric side of OLb1905f on LG 23. In strain 2, two markers on LG 5, Mf01SSA017E11 and MF01SSA102C03, had high concordance rates (both 92.6\%) (Figure 6b). To obtain a completely linked marker, we examined two additional markers (MF01SSA013C06 and MF01SSA035D11). These markers had respective concordance rates of 96.3 and $100 \%$, indicating that exogenous DMY was located between MF01SSA013C06 and MF01SSA102C03 on LG 5 . In addition, no markers had high concordance rates with other LGs in either strain, suggesting that in both strains exogenous DMY was integrated into one locus.

Next, we used real-time PCR to examine the copy number and expression levels of exogenous DMY during the period of sex determination. The comparative $\mathrm{Ct}$ method revealed that the copy number of strain 1 was 2.0 and that of strain 2 was 10.9 relative to that in the $\mathrm{Hd}$ rR. ${ }^{H N I}$ strain (Table 3). The expression level of exogenous DMY relative to that in Hd-rR. $\mathrm{Y}^{\mathrm{HNI}}$ on hatching day was 1.6 in strain 1 and 10.6 in strain 2 . This suggests that strain 1 had 2 copies of exogenous DMY and strain 2 had 11 copies, and the expression levels were proportional to the copy numbers, suggesting that there was no negative feedback mechanism in the transcriptional regulation of DMY.

\section{Discussion}

\section{Artificial sex chromosomes in vertebrates}

Present results show that two DMY-transgenic strains, in which the exogenous DMY gene determines the sex of individuals, were established. Our results also show that LGs 23 and 5 functioned as sex chromosomes in $D M Y$-transgenic strains 1 and 2, respectively. Transgenic insertion of $D M Y$ has made an autosome into a sex chromosome in other words, the DMY-transgenic strains each had an artificial $\mathrm{Y}$ chromosome.

Chromosomal sex determination is widely used by vertebrates such as many fish and reptiles, all amphibians, birds and mammals. Although the origin of sex chromosomes may differ among taxa, it is hypothesized that sex chromosomes are derived from autosomes (Charlesworth et al., 2005). The most studied sex chromosomes are $\mathrm{X}$ and $\mathrm{Y}$ in mammals and $\mathrm{Z}$ and $\mathrm{W}$ in birds and snakes. These sex chromosome pairs are morphologically distinct and contain several chromosome-specific genes. According to standard models for sex chromosome evolution, heteromorphic sex chromosomes are thought to arise through suppression of recombination around the sex-determining gene, maintaining the non-recombining region in a constantly heterozygous state and leading to numerous deletions of functional genes and the accumulation of repetitive sequences. This degenerative process spreads the sexspecific region over almost the entire chromosome, and several genes with sex-specific advantages accumulate. In the mouse, besides Sry, two male-specific genes, an RNA-binding motif ( $R b m$ ) gene and the ubiquitinactivating enzyme gene (Ube1y), are located on the $Y$ chromosome (Kay et al., 1991; Mitchell et al., 1991; Elliott et al., 1996). These genes are expressed in spermatogonia and spermatids (Odorisio et al., 1996; Mahadevaiah et al., 1998); a deletion mutant of the $Y$ chromosome that had lost these genes had a high incidence of sperm abnormalities (Mahadevaiah et al., 1998). These results indicate that $\mathrm{Rbm}$ and Ube1y are required for spermatogenesis, and that the lack of these genes is the cause of the sterility observed in the Sry-transgenic mouse (Koopman et al., 1991). Thus, a high level of differentiation of sex chromosomes is likely to act as a barrier to the production of artificial sex chromosomes in mammals. In contrast to mammals, sex chromosomes are homomorphic in medaka. The sex-determining region on the $\mathrm{Y}$ chromosome and the corresponding region on the $\mathrm{X}$ 

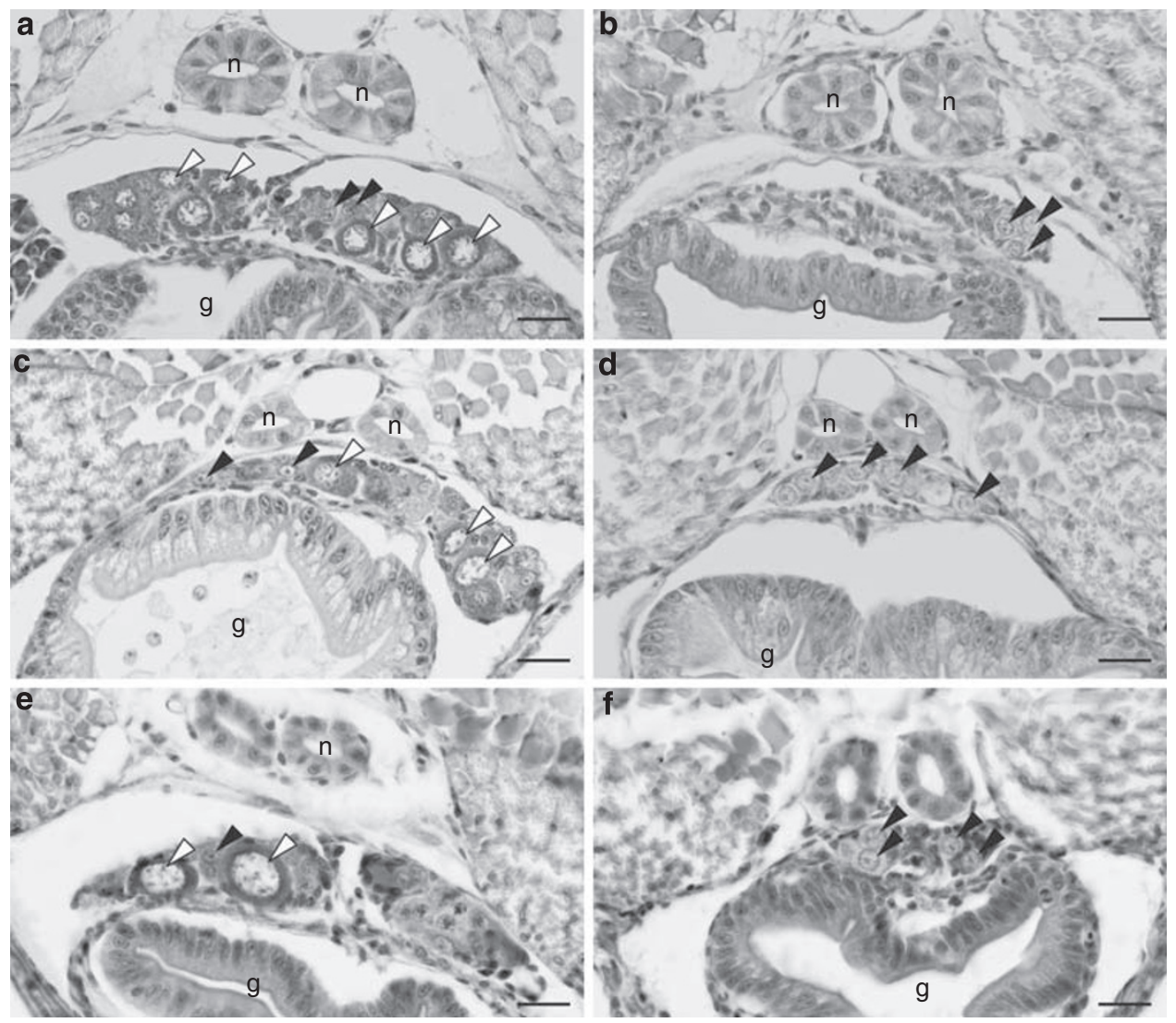

Figure 5 Gonadal sex differentiation in the DMY-transgenic strains at 10 days after hatching. Representative gonadal histologies of normal XX female (a), normal XY male (b), transgene-negative (c), and transgene-positive (d) fish in strain 1 and transgene-negative (e) and transgene-positive (f) fish in strain 2. Black arrowheads indicate gonia and white arrowheads indicate diplotene-stage oocytes. $n$, nephric duct; g, gut. Bars, $20 \mu \mathrm{m}$.

chromosome were recently fully sequenced. The Yspecific region proved to be $258 \mathrm{~kb}$ long and $D M Y$ appeared to be the only functional gene in this region (Kondo et al., 2006). In addition, we found a wild medaka population in which $\mathrm{Y}$ chromosomes bearing a loss-offunction $D M Y$ mutation were present in one-third of females (Otake et al., 2008). In this population, the $Y$ chromosome, which has lost its male-determining function, behaves as an $\mathrm{X}$ chromosome. These results reveal that in medaka, the difference between the $X$ and $Y$ chromosomes is defined only by the absence or presence of $D M Y$. Here, we show that the introduction of $D M Y$ is sufficient to produce an artificial sex chromosome in this species. Furthermore, unlike Sry, DMY appears to have arisen from duplication of the autosomal DMRT1 gene and its insertion into LG 1 (Kondo et al., 2006). This event suggests that any chromosome could have become the sex chromosome in the ancestor of medaka.

\section{Plasticity of sex chromosomes in lower vertebrates}

The mammalian XY sex-determining system appears to be at least 150 million years old, since SRY orthologs have been identified on the $Y$ chromosome in both branches of therian mammals, placentals and marsupials (Waters et al., 2007), except for a few exceptional rodents that have recently lost their Y chromosome (Just et al., 1995). The avian $\mathrm{ZW}$ sex-determining system is likely to have appeared between 60 and 100 million years ago according to fossil, cytogenetic and molecular data (Harlid et al., 1997; Shetty et al., 1999). Hence, higher vertebrate species seem to have conserved their sex chromosomes in their long lineage.

On the other hand, no consistent sex-specific chromosomes have been observed in fish and amphibians with genetic sex determination that would suggest conservation of sex chromosomes (Schmid and Steinlein, 2001; Devlin and Nagahama, 2002). Recent studies have shown that the sex chromosomes in two medaka-related species, $O$. luzonensis and O. dancena, are homologous to different autosomes in medaka (Takehana et al., 2007; Tanaka et al., 2007). Similar phenomena have been observed in salmonids and sticklebacks, suggesting that sex chromosomes have changed frequently in fish (Woram et al., 2003; Peichel et al., 2004; Phillips et al., 2007). In the Japanese frog, Rana rugosa, two distinct sex chromosome types, XX/ $\mathrm{XY}$ and $\mathrm{ZZ/ZW}$, were observed in the same species (Miura et al., 1998). In addition, the change of heterogametic sex from male to female appears to have independently occurred twice during frog speciation (Ogata et al., 2008). These results suggest that the sex chromosomes are generally not conserved in lower vertebrates. Our results show that switching of sex chromosomes can occur easily through the generation of new master sex-determining genes in vertebrates that possess homomorphic sex chromosomes. This plasticity 

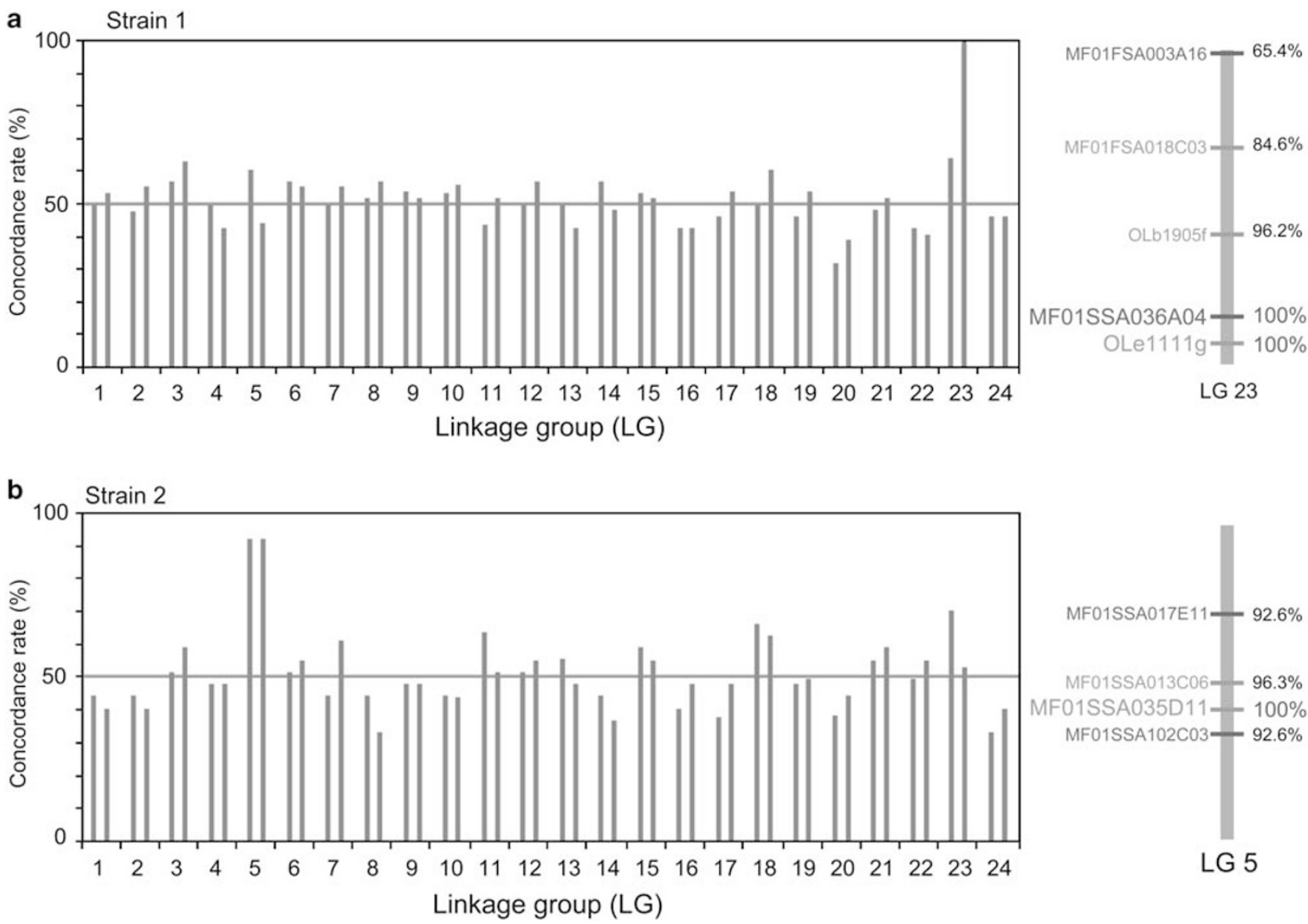

Figure 6 Mapping of the transgene in DMY-transgenic strains. The concordance rates of each M-marker are shown by solid bars for strain 1 (a) and strain 2 (b) in the graphs on the left. Positions of the markers that showed high concordance rates are represented on the right. Markers with $100 \%$ concordance rates were found in linkage group 23 in strain 1 and in linkage group 5 in strain 2.

Table 3 Copy number and expression level of exogenous DMY in the transgenic strains

\begin{tabular}{|c|c|c|c|c|c|c|c|c|}
\hline \multirow[t]{2}{*}{ Strain } & \multicolumn{3}{|c|}{ Copy number } & \multicolumn{5}{|c|}{ Expression level } \\
\hline & Average Ct (DMY) & $\Delta C t$ & $\begin{array}{l}\text { Relative to } \\
H d-r R . Y^{H N I}\end{array}$ & Average Ct (DMY) & $\begin{array}{c}\text { Average } \\
C t(E F-1 a)\end{array}$ & $\Delta C t$ & $\Delta \Delta C t$ & $\begin{array}{l}\text { Relative to } \\
H d-r R . Y^{H N I}\end{array}$ \\
\hline Hd-rR. $Y^{\mathrm{HNI}}$ & $24.63 \pm 0.03$ & 0 & 1 & $29.41 \pm 0.39$ & $18.24 \pm 0.16$ & $11.17 \pm 0.49$ & 0 & 1 \\
\hline Strain 1 & $23.63 \pm 0.07$ & $1.00 \pm 0.09$ & $2.0(1.9-2.1)$ & $28.92 \pm 0.58$ & $18.42 \pm 0.13$ & $10.5 \pm 0.69$ & $-0.67 \pm 0.69$ & $1.59(0.99-2.57)$ \\
\hline Strain 2 & $21.18 \pm 0.13$ & $3.45 \pm 0.15$ & $10.9(9.8-12.1)$ & $25.79 \pm 0.38$ & $18.03 \pm 0.18$ & $7.76 \pm 0.49$ & $-3.41 \pm 0.49$ & $10.63(14.93-7.57)$ \\
\hline
\end{tabular}

appears to underlie the frequent switching of sex chromosomes observed in fish and frogs. As many lower vertebrate species have morphologically homomorphic sex chromosomes (Schmid and Steinlein, 2001; Devlin and Nagahama, 2002), this plasticity may be a characteristic of lower vertebrates that is not found in higher vertebrates.

\section{Conflict of interest}

The authors declare no conflict of interest.

\section{Acknowledgements}

We thank Dr H Wada of Niigata University for his invaluable suggestions on the manuscript. This work was supported, in part, by a Japan Society for the Promotion of Science (JSPS) fellowship (to HO).

\section{References}

Aida T (1921). On the inheritance of color in a fresh-water fish, Aplocheilus latipes Temmick and Schlegel, with special reference to sex-linked inheritance. Genetics 6: 554-573.

Charlesworth D, Charlesworth B, Marais G (2005). Steps in the evolution of heteromorphic sex chromosomes. Heredity 95: 118-128.

Devlin RH, Nagahama Y (2002). Sex determination and sex differentiation in fish:an overview of genetic, physiological, and environmental inf luences. Aquaculture 208: 191-364. 
Elliott DJ, Ma K, Kerr SM, Thakrar R, Speed R, Chandley AC et al. (1996). An RBM homologue maps to the mouse $Y$ chromosome and is expressed in germ cells. Hum Mol Genet 5: 869-874.

Gubbay J, Collignon J, Koopman P, Capel B, Economou A, Munsterberg A et al. (1990). A gene mapping to the sexdetermining region of the mouse $\mathrm{Y}$ chromosome is a member of a novel family of embryonically expressed genes. Nature 346: 245-250.

Harlid A, Janke A, Arnason U (1997). The mtDNA sequence of the ostrich and the divergence between paleognathous and neognathous birds. Mol Biol Evol 14: 754-761.

Just W, Rau W, Vogel W, Akhverdian M, Fredga K, Graves JA et al. (1995). Absence of Sry in species of the vole Ellobius. Nat Genet 11: 117-118.

Kay GF, Ashworth A, Penny GD, Dunlop M, Swift S, Brockdorff $\mathrm{N}$ et al. (1991). A candidate spermatogenesis gene on the mouse $\mathrm{Y}$ chromosome is homologous to ubiquitin-activating enzyme E1. Nature 354: 486-489.

Kimura T, Jindo T, Narita T, Naruse K, Kobayashi D, Shin IT et al. (2004). Large-scale isolation of ESTs from medaka embryos and its application to medaka developmental genetics. Mech Dev 121: 915-932.

Kinoshita M, Haruhiko T, Morihiko S, Koji I, Shinya Y, Mikio $S$ et al. (1996). A stable line of transgenic medaka (Oryzias latipes) carrying the CAT gene. Aquaculture 143: 267-276.

Kobayashi T, Matsuda M, Kajiura-Kobayashi H, Suzuki A, Saito N, Nakamoto M et al. (2004). Two DM domain genes, DMY and DMRT1, involved in testicular differentiation and development in the medaka, Oryzias latipes. Dev Dyn 231: 518-526.

Kondo M, Hornung U, Nanda I, Imai S, Sasaki T, Shimizu A et al. (2006). Genomic organization of the sex-determining and adjacent regions of the sex chromosomes of medaka. Genome Res 16: 815-826.

Koopman P, Gubbay J, Vivian N, Goodfellow P, Lovell-Badge R (1991). Male development of chromosomally female mice transgenic for Sry. Nature 351: 117-121.

Livak KJ, Schmittgen TD (2001). Analysis of relative gene expression data using real-time quantitative PCR and the 2(-Delta Delta C(T)) method. Methods 25: 402-408.

Mahadevaiah SK, Odorisio T, Elliott DJ, Rattigan A, Szot M, Laval SH et al. (1998). Mouse homologues of the human AZF candidate gene RBM are expressed in spermatogonia and spermatids, and map to a Y chromosome deletion interval associated with a high incidence of sperm abnormalities. Hum Mol Genet 7: 715-727.

Matsuda M, Matsuda C, Hamaguchi S, Sakaizumi M (1998). Identification of the sex chromosomes of the medaka, Oryzias latipes, by fluorescence in situ hybridization. Cytogenet Cell Genet 82: 257-262.

Matsuda M, Nagahama Y, Shinomiya A, Sato T, Matsuda C, Kobayashi T et al. (2002). DMY is a Y-specific DM-domain gene required for male development in the medaka fish. Nature 417: 559-563.

Matsuda M, Sato T, Toyazaki Y, Nagahama Y, Hamaguchi S, Sakaizumi M (2003). Oryzias curvinotus has DMY, a gene that is required for male development in the medaka, $\mathrm{O}$. latipes. Zoolog Sci 20: 159-161.

Matsuda M, Shinomiya A, Kinoshita M, Suzuki A, Kobayashi T, Paul-Prasanth B et al. (2007). DMY gene induces male development in genetically female (XX) medaka fish. Proc Natl Acad Sci USA 104: 3865-3870.

Mitchell MJ, Woods DR, Tucker PK, Opp JS, Bishop CE (1991). Homology of a candidate spermatogenic gene from the mouse $Y$ chromosome to the ubiquitin-activating enzyme E1. Nature 354: 483-486.

Miura I, Ohtani H, Nakamura M, Ichikawa Y, Saitoh K (1998). The origin and differentiation of the heteromorphic sex chromosomes $\mathrm{Z}, \mathrm{W}, \mathrm{X}$, and $\mathrm{Y}$ in the frog Rana rugosa, inferred from the sequences of a sex-linked gene, ADP/ATP translocase. Mol Biol Evol 15: 1612-1619.

Nanda I, Kondo M, Hornung U, Asakawa S, Winkler C, Shimizu A et al. (2002). A duplicated copy of DMRT1 in the sex-determining region of the $\mathrm{Y}$ chromosome of the medaka, Oryzias latipes. Proc Natl Acad Sci USA 99: 11778-11783.

Odorisio T, Mahadevaiah SK, McCarrey JR, Burgoyne PS (1996). Transcriptional analysis of the candidate spermatogenesis gene Ube1y and of the closely related Ube1x shows that they are coexpressed in spermatogonia and spermatids but are repressed in pachytene spermatocytes. Dev Biol 180: 336-343.

Ogata M, Hasegawa Y, Ohtani H, Mineyama M, Miura I (2008). The ZZ/ZW sex-determining mechanism originated twice and independently during evolution of the frog, Rana rugosa. Heredity 100: 92-99.

Ogata M, Ohtani H, Igarashi T, Hasegawa Y, Ichikawa Y, Miura I (2003). Change of the heterogametic sex from male to female in the frog. Genetics 164: 613-620.

Otake H, Hayashi Y, Hamaguchi S, Sakaizumi M (2008). The Y chromosome that lost the male-determining function behaves as an $\mathrm{X}$ chromosome in the medaka fish, Oryzias latipes. Genetics 179: 2157-2162.

Peichel CL, Ross JA, Matson CK, Dickson M, Grimwood J, Schmutz J et al. (2004). The master sex-determination locus in threespine sticklebacks is on a nascent $\mathrm{Y}$ chromosome. Curr Biol 14: 1416-1424.

Pfaffl MW (2001). A new mathematical model for relative quantification in real-time RT-PCR. Nucleic Acids Res 29: e45.

Phillips RB, DeKoning J, Morasch MR, Park LK, Devlin RH (2007). Identification of the sex chromosome pair in chum salmon (Oncorhynchus keta) and pink salmon (Oncorhynchus gorbuscha). Cytogenet Genome Res 116: 298-304.

Raymond CS, Shamu CE, Shen MM, Seifert KJ, Hirsch B, Hodgkin J et al. (1998). Evidence for evolutionary conservation of sex-determining genes. Nature 391: 691-695.

Satoh N, Egami N (1972). Sex differentiation of germ cells in the teleost, Oryzias latipes, during noraml embryonic development. J Embryol Exp Morphol 28: 385-395.

Schmid M, Steinlein C (2001). Sex chromosomes, sex-linked genes, and sex determination in the vertebrate class amphibia. EXS 91: 143-176.

Shetty S, Griffin DK, Graves JA (1999). Comparative painting reveals strong chromosome homology over 80 million years of bird evolution. Chromosome Res 7: 289-295.

Shinomiya A, Matsuda M, Hamaguchi S, Sakaizumi M (1999). Identification of genetic sex of the medaka, Oryzias latipes, by PCR. Fish Biol J Medaka 10: 31-32.

Shinomiya A, Otake H, Togashi K, Hamaguchi S, Sakaizumi M (2004). Field survey of sex-reversals in the Medaka, Oryzias latipes: Genotypic sexing of wild populations. Zoolog Sci 21: 613-619.

Shinomiya A, Tanaka M, Kobayashi T, Nagahama Y, Hamaguchi S (2000). The vasa-like gene, olvas, identifies the migration path of primordial germ cells during embryonic body formation stage in the medaka, Oryzias latipes. Dev Growth Differ 42: 317-326.

Sinclair AH, Berta P, Palmer MS, Hawkins JR, Griffiths BL, Smith MJ et al. (1990). A gene from the human sexdetermining region encodes a protein with homology to a conserved DNA-binding motif. Nature 346: 240-244.

Takehana Y, Demiyah D, Naruse K, Hamaguchi S, Sakaizumi M (2007). Evolution of different $Y$ chromosomes in two medaka species, Oryzias dancena and O. latipes. Genetics 175: $1335-1340$.

Tanaka K, Takehana Y, Naruse K, Hamaguchi S, Sakaizumi M (2007). Evidence for different origins of sex chromosomes in closely related Oryzias fishes: Substitution of the master sex-determining gene. Genetics 177: 2075-2081.

Tanaka M, Kinoshita M, Kobayashi D, Nagahama Y (2001). Establishment of medaka (Oryzias latipes) transgenic lines with the expression of green fluorescent protein fluorescence 
exclusively in germ cells: a useful model to monitor germ cells in a live vertebrate. Proc Natl Acad Sci USA 98: 2544-2549.

Waters PD, Wallis MC, Marshall Graves JA (2007). Mammalian sex-origin and evolution of the $\mathrm{Y}$ chromosome and SRY. Semin Cell Dev Biol 18: 389-400.
Woram RA, Gharbi K, Sakamoto T, Hoyheim B, Holm LE, Naish $\mathrm{K}$ et al. (2003). Comparative genome analysis of the primary sex-determining locus in salmonid fishes. Genome Res 13: 272-280.

Zarkower D (2001). Establishing sexual dimorphism: conservation amidst diversity? Nat Rev Genet 2: 175-185.

Supplementary Information accompanies the paper on Heredity website (http://www.nature.com/hdy) 